\title{
Comparative Study of Leadership Competences of Female and Male Mexican Expatriates
}

\author{
Erika Lourdes González Rosas \\ University of Guanajuato, Guanajuato México \\ E-mail: gonzalez@ugto.mx \\ Martha Leticia Guevara-Sanginés \\ University of Guanajuato, Guanajuato México \\ E-mail: leticiag@ugto.mx \\ Martin P. Pantoja Aguilar \\ University of Guanajuato, Guanajuato México \\ E-mail: pantojam@ugto.mx \\ Luz Adriana Sancén \\ Southern Oregon University, Ashland, Oregon USA \\ E-mail: luzsancen.ls@gmail.com
}

Received: April 4, 2017 Accepted: May 8, 2017 Published: May 26, 2017

doi:10.5296/csbm.v4i1.11284ＵRL: http://dx.doi.org/10.5296/csbm.v4i1.11284

\begin{abstract}
The purpose of this study is to compare female and male leadership competences of Mexican expatriates in the USA, using a qualitative approach. A case study was conducted through a narrative analysis of the information. The study also revised the factors that contributed to the leadership competences of expatriates. The responses of a single female and a single male Mexican expatriates were collected through open responses using an electronic questionnaire. The research questions were: What are the leadership competences of Mexican expatriates? Which are the main differences between women's and men's leadership competences in Mexican expatriates? The comparison was made using Pablo Cardona's model of
\end{abstract}




\section{Macrothink}

Case Studies in Business and Management

ISSN 2333-3324

2017, Vol. 4, No. 1

competences. Since leadership competences are observable behaviors, a narrative analysis was conducted and some key differences were found between male and female leadership competences. For example, it appears that Mexican male expatriates tend to focus on leadership, receptiveness and informal features; while women focus on values, information and formal position. Common features were found between both interviewees concerning work and personal life related to time management competence. As future research, a quantitative analysis is required to corroborate these findings.

Keywords: Leadership, Expatriates, Gender, Competences 


\section{Introduction}

The results of this work can provide a framework for the study of development of expatriates at work in different environments. This study provides information useful to understanding how to work with Mexican expatriates in American businesses considering their leadership competences. It identified the main differences between men and women's leadership competences in an expatriate situation, since "Cross-cultural leadership literature has demonstrated various beliefs about leadership across cultures” (Dickson et al., 2003; Martin et al., 2009).

An investigation was conducted in order to compare female and male leadership competences using a qualitative approach through a narrative analysis. The research questions were: What are the leadership competences in Mexican expatriates? And which are the main differences between women's and men's leadership competences in Mexican expatriates?

All over the world, a large number of companies are using expatriate employees for their production and administration processes. This situation is becoming more common every year and represents a vital part of the company. Nevertheless, not all companies are giving attention to human resources developing programs for expatriate employees. This becomes an important issue since Mexicans have leadership particularities based on their culture. That is why it is important to understand and analyze those particularities in the business and executive environment because some expatriates perform leader roles in foreign countries. Based on the above, this study develops a research project oriented to identifying different leadership competences of Mexican expatriates in the USA. The aim of this study is to contribute to generate significant knowledge for companies making decisions related to programs of development for expatriates considering that leadership style is an important issue and is influenced by culture and the expatriate's experience.

\section{Literature Review}

\subsection{Expatriates Review}

The study of the expatriate work situation has been important in literature studies. As an example, Dabic, González-Loureiro, \& Harvey (2015) found that in the last forty years 438 papers on the expatriate condition were published in 104 different journals by 233 authors. Moreover, Hsing-Chau, Lin-Yuan, \& Kuo-Hsun (2010) in a similar study found that research on the expatriate condition is organized mainly on three main topics: expatriate adjustment, global leadership and repatriation adjustment.

Research on expatriate condition has been developed widely and it has been studied across many different fields. An example is the study on satisfaction, opportunities and challenges for Koreans living in India conducted by Kim \& Tung (2013) in which it was identified that Confucius's values brought by Koreans have a significant impact on the Indian environment. Another example is the study on German managers and their subordinates in China conducted by Patrick Rau, Jun, Juzek, \& Reiner Nowacki (2013) in which it was identified that the Chinese employees prefer higher power distance from their leaders. Based on those differences obtained it is important for leaders around the world to develop the right style of 
leadership that can also suit the culture of expatriates.

Another current topic related to expatriate condition is stress. Stress has been pointed out as one the main factors that expatriates have to face at work and it is highly documented in role ambiguity and role novelty as well (Kawai \& Mohr, 2015). But it also remains a main factor even in the performance of expatriate teams where native culture did not have a significant impact (O’Sullivan \& O’Sullivan, 2008).

In the analysis of expatriate performance, it is important to consider individual, social, organizational and environmental factors. All of these factors integrate to form cultural intelligence, and it is basic to expatriates and their families during the adaptation process (Krishnaveni \& Arthi, 2015). There are cases of self-initiated expatriates where consequences have been studied considering context and careers (Rodriguez \& Scurry, 2014). The human resources management of a business is a key factor for the satisfaction of psychological and organizational needs of expatriates, especially considering interpersonal skills and self-efficiency. Additionally, the importance of training has been pointed out by Popovski, Popovska, \& Jovcheska (2014).

\subsection{Expatriates and Leadership}

There are several cases of leadership being adapted to cultural environments. Chaudhuri \& Alagaraja (2014) provide a case of an American manager who worked several years in India and explained that he had to adapt his leadership according to the Indian culture by using some of the concepts of Ghandi, above other personal thoughts. Adapting leadership is a significant issue since many times expatriates hold leadership positions. In such a condition, expatriate leaders have to consider many factors in order to perform efficiently. The importance of the local managers has also been pointed out by Berger, Choi, \& Kim (2011).

Leadership of expatriates has been studied in different ways and Suutari (1998) provides evidence in his study of Finnish expatriates. He claims that Finnish managers located in Russia and Estonia were less active and changed their leadership style. On the other hand, Suutari (1996) notices that the nationality of expatriates also is expected to influence their leadership style.

In the paste, several studies comparing two types of leadership have been conducted as cross cultural leadership research. For example, a study was conducted in the United Arab Emirates where managers from several countries were evaluated according to their leadership style. It was found that managers in this country were less transformational than their counterparts in the US or Europe (Bealer \& Bhanugopan, 2014). Another study analyzed the difference between Polish and Western managers, and it identified different styles of leadership where some preferred local or western managers (Eisenberg, Pieczonka, Eisenring, \& Mironski, 2015). Nevertheless, it is important to recognize that in a separated case, in which task oriented and power relationships were analyzed between Chinese and Westerns managers located in China, no big differences were found (Wong, Wong, \& Li, 2007). Also, the case of task and relation orientated leadership between expatriate managers and professionals who are working with German-born workers have been explored (Nguyen, Boehmer, \& Mujtaba, 
2012).

The point of view of followers is fundamental for leadership and also in the case of expatriates. Expectations of followers and their poor identification with the leader have been also studied in the case of expatriates (Stock \& Özbek-Potthoff, 2014). On the other hand, leadership is not always successful for expatriates, an example are the several global Japanese companies who struggle very hard to be successful in foreign countries, a fact that is highly documented (Black \& Morrison, 2012; Berger, Choi, \& Kim, 2011).

\subsection{Leadership Competences}

This project uses Pablo Cardona's leadership model that it is based on four types of competences: businesses, interpersonal, and internal and external personal competences. Every competence is an observable behavior that has an orientation towards action. Itis oriented to have success in a function or activity. Business competence is oriented to obtain economic value for the company. The interpersonal competence is focused on developing new abilities in followers and lead them to good job performance. Personal competences search for trust and identification with followers. Personal competences are external and internal. External personal competence is the ability of response to external stimulus. Internal personal competence is related to a more intimate aspect of the person. Based on the four general types of competences, Cardona identified ten main specific competences: creative initiative, decision making, communication, empowerment, customer focus, integrity, teamwork, resilience, time management and conflict management (Cardona \& García Lombardía, 2009; Cardona \& Wilkinson, 2009). Those particular competences are defined as follows:

1) Creative Initiative: Demonstrates entrepreneurial behavior by initiating and promoting the need for changes with energy and accountability.

2) Decision Making: Accurate and timing decision making.

3) Teamwork: Promotes a collaborative environment, with open communication and trust among team members.

4) Communication: Listen and share ideas effectively throughout an adequate channel, in the right moment, providing specific information to support observations and conclusions.

5) Empowerment: Inspire trust in team members by giving meaningful assignments and motivating them to achieve objectives.

6) Customer Focus: Obtains customer satisfaction by providing a valued offer, taking care of all aspects in the relationship and responding to their requirements and suggestions.

7) Resilience: Obtains new knowledge, change habits and is open to change.

8) Integrity: Demonstrates straight and honest behavior in all circumstances.

9) Time Management: Prioritize objectives, schedule activities properly and actionize them according to a plan.

10) Conflict Management: Diagnose, confront and solve interpersonal conflicts from the root and on time, without harming personal relationships (Cardona \& Wilkinson, 2009, pp. 53-201). 


\subsection{Mexican Culture}

To conduct studies on leadership of expatriates, the original culture is a variable that must be deeply considered in the analysis. For this study, it is important to include a background of the Mexican culture for business and its executive men and women. Mexico has almost two millions square kilometers and 121million habitants, and the average family income is almost ten thousand and six hundred dollars per year. While doing business in Mexico you may face low ethical standards in politics, excessive consumption and materialism, high levels of poverty and a huge disconnection between values espoused by the Roman Catholic Church and business practices (Ardivichvili, Jondle, \& Kowske, 2010).

Mexico was placed in 39th place in the World Bank’s “Doing Business 2015 report”. The Mexican government boasts that it takes only six days, in six procedures, for any investor to open a business. Mexico was also placed on the 61st place in the Global Competitiveness Index 2014-2015. Moreover, Mexico was placed on the 41st position in the IMD World Competitiveness Yearbook, still above countries like Brazil, the Philippines, India and Portugal (Pro Mexico, 2015).

Doing business or working with Mexicans has several peculiarities. Doing successful business in Mexico is also about adapting leadership to the Mexican culture. It is considered that Personal relationship is a key issue for business success in Mexico, and the only way to know a person in Mexico is to know the family. Mexicans first and foremost do business with people. They cannot relate just with impersonal organizations. It is very important that businessmen develop a personal relationship. It requires time to develop your business relations in Mexico since trust is very important and Mexicans will take time to establish trust (Chamoun-Nicolas, 2011). It has been said that in order to work with Mexicans it is necessary to know the culture and social aspects are relevant, but it is also important to consider the Mexican economy.

\subsection{The Multinational}

Regarding to INEGI (2014) the automotive industry started to grow in the state of Guanajuato, Mexico, in the 90's and it has been growing significantly since then (60\% from 2009 to 2012). One of the most important automotive multinational companies in the world has a manufacturing plant in Guanajuato. For the purposes of this work it will be referenced as the "The Multinational”. The presence in Mexico of the "The Multinational" starts in 1963 and currently has five sites:

- Ramos Arizpe-Coahuila. It is located at the north of the country. There are two plants in the complex: Assembly and engines. Both plants are designed for small cars.

- Silao-Guanajuato. It is located in central México. It has three plants: Assembly, engines and transmissions. The complex's production is for full size pickups.

- Toluca-Estado de México. This facility has two plants: Foundry and engine plants.

- San Luis Potosí-San Luis Potosí. There are two plants in this facility: Small cars assembly plant and transmissions plant. 


\section{Macrothink}

Case Studies in Business and Management

ISSN 2333-3324

2017, Vol. 4, No. 1

- Siglo XXI-Ciudad de México. “The Multinational” national headquarters are located in Mexico City, the capital city. In the headquarters several activities are undertaken: sales, legal issues, purchasing and general management, among others.

Being a global company, “The Multinational” develops employees to be leaders capable of bringing the company to higher levels. Through the company's mission, the leaders share knowledge, promote standardization and continue improvement. With this purpose, "The Multinational" has established a global job opportunities program, in which every employee has the opportunity to receive information and to self-nominate for job openings on a global basis.

Employees who are in an international assignment are called International Service Personnel or ISP. From the host country perspective those employees are named inbound employees. From the home country viewpoint those employees are classified as outbound. "The Multinational” employs an average of 150 expatriates per year across the globe, distributed as follows in figures 1 and 2 .

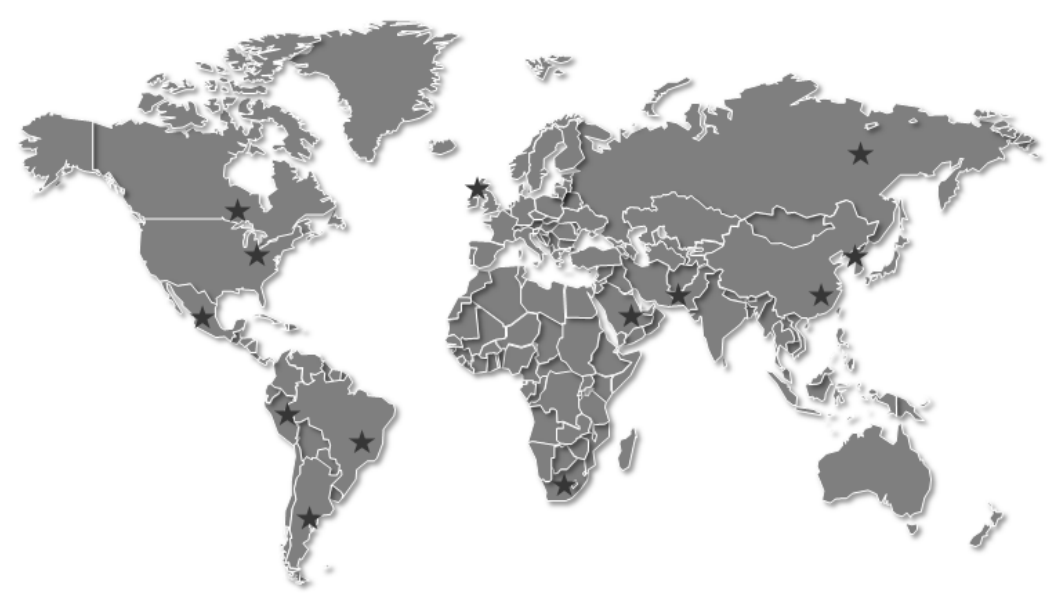

Figure 1. Map of expatriates

Source: Confidential Data of the Multinational, 2016.

"The Multinational” has a "Global International Service Personnel Policy" in place which is very friendly with employees. The policy establishes a compensation basis, job descriptions, clear responsibilities, detailed requirements, etc. in a global application for short and long term assignments. 


\section{Total}

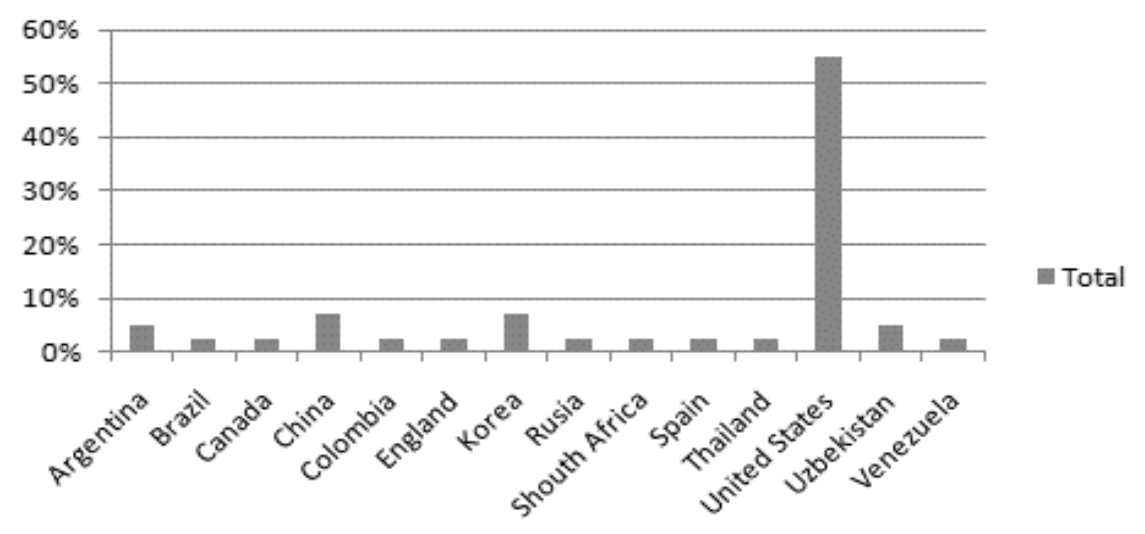

Figure 2. Percentage of expatriates

Source: Confidential Data of the Multinational, 2016.

Compensation and benefits in long term assignments include: living cost allowance, destination premium, housing allowance; relocation allowance, international mobility premium, spousal career continuation; utilities, school allowance, salary differential; language training, accommodation expenses and tax protection policy.

\section{Methodology}

\subsection{Objective and Research Questions}

The goal of this study was to obtain information on leadership competences through a comparison between female and male Mexican expatriates using a qualitative approach to identify the main differences. The comparison was made using Pablo Cardona's model concerning competences in leadership.

The research questions were: What are the leadership competences in Mexican expatriates? and, Which are the main differences between woman and man leadership competences in Mexican expatriates?

The design of the research is qualitative and narrative. It has been defined as "qualitative procedures in which researchers describe the lives of individuals, collect and tell stories about these individuals' lives, and write narratives about their experiences". There is an investigation into the life stories of one or two individuals (Creswell, 2012, p. 22).

\subsection{Case Study}

A case study has been defined as in-depth exploration of a bounded system based on data collection (Creswell, 2007). In this research a case study was done through a narrative analysis of the information. The study examined what factors contributed to leadership competences in female and male expatriates. The information was collected through open responses that were obtained by an electronic questionnaire applied to one female Mexican 
expatriate and one male Mexican expatriate. The questionnaire was send by email to the participants to obtain the data.

\subsection{Participants}

The participants were one female and one male Mexican expatriate executives. The female is 36 years old, and she is a Software Development Engineer, holds a Bachelor degree in Systems from Ramos Arizpe, Coahuila, Mexico. She has been an expatriate for one year and has worked for the company for seven years and coordinates two subordinates. The male is 32 years old, he works as a Design Release Engineer, holds a bachelor degree in Industrial and Systems Engineering from Toluca, Mexico. He has worked for four years for the company, two in Mexico and two in the USA, and he coordinates ten people.

\subsection{Questionnaire}

In order to identify the variables, a questionnaire with sixteen open questions was designed. The questionnaire was send by email to the participants who are working in Michigan, USA. Both questionnaires were posted back and by email as well.

\section{Results}

At first, a comprehensive reading of the questionnaires was undertaken to scan the content. The information was then codified identifying the significance of the participants' responses. The codes for the responses were defined considering the research variables detecting the categories regarding the experiences of the participants. Finally, a table was created with the information of both participants. This work was based on the data received and inferences were developed considering the narrative speech of the participants.

\subsection{Narrative Analysis}

Table 1 presents a summary of the categories and the different codes found for each variable. 
Table 1. Categories of the variables

\begin{tabular}{|l|l|l|}
\hline Cardona's category & Female code & Male code \\
\hline Creative Initiative & In group & $\begin{array}{l}\text { Strong, positive, feedback and } \\
\text { learning }\end{array}$ \\
\hline Decision Making & Values & Experience and advising \\
\hline Teamwork & Training & Proactive and leadership \\
\hline Communication & Formal & Informal and receptive \\
\hline Empowerment & Group and project & Leadership and teamwork \\
\hline Customer Focus & Information & Listen and finding needs \\
\hline Resilience & Leadership & $\begin{array}{l}\text { Leadership, trust, character and } \\
\text { communication }\end{array}$ \\
\hline Integrity & Values & Opportunities \\
\hline Time Management & Work and personal life & Work and personal life \\
\hline Conflict Management & Listen & Negotiate \\
\hline
\end{tabular}

In the following paragraphs the narrative analyzed for each category is detailed. Both responses, female and male, are presented to identify leadership competences.

\subsubsection{Creative Initiative Category}

This category shows how people do their entrepreneurship activities, the level of energy and personal responsibility.

Female: “Through company groups”.

Male: "Strong but not aggressive, positive, open to any kind of feedback and willing to learn from anything and anyone".

\subsubsection{Decision Making Category}

Decision making has to deal with the right and opportune decision.

Female: “Company policies, vision and values of the company as well as own values”. Male: "Previous experiences, tools (software and hardware if any), approach and ask other co-workers for their advice for same or similar situations, guides, standards, support center".

\subsubsection{Teamwork Category}

This category states the level of collaboration, communication and trust between the members of a team.

Female: "Open, fluent, supportive, depends on each individual... Supporting team work through courses, training and HR workshops".

Male: "More active, open, fluent, very good team players I have met so far, friendly and focused in one direction "to achieve the goal”, strong leadership adds a human touch". 


\section{Macrothink \\ Case Studies in Business and Management \\ ISSN 2333-3324 \\ 2017, Vol. 4, No. 1}

\subsubsection{Communication Category}

This category states the quality of communication, the listening and efficient transmission of the correct amount of information.

Female: "Through post in whiteboards, emails, meetings".

Male: "Direct and open, making people to feel free to ask for any support that could be needed".

\subsubsection{Empowerment Category}

Empowerment is about motivating followers to give sense to their work and to achieve their objectives.

Female: "It allows developing skills, capacities and revealing risk points on both sides.

Focus on the group and projects".

Male: "It develops the leadership skill, gives a sense of "importance to the company" to the co-worker who receives the task, build and develop the team work. When this is over used, the opposite occurs".

\subsubsection{Customer Focus Category}

This category is about satisfying the clients' needs and expectations.

Female: "With the information provided by them"

Male: "Paying attention to their request, listening to their currents needs, shadowing them in their daily task and more. This way I can understand what they are asking for and why (the reason)".

\subsubsection{Resilience Category}

In this category, the leader must acquire new knowledge, modify habits and be open to change.

Female: "Leadership, taking into consideration the actual leadership definition".

Male: "Leadership, confidence, strong and friendly character (not aggressive), communicative, humble, transparency and human”.

\subsubsection{Integrity Category}

Integrity category is about alignment between values and behaviors.

Female: "Values that are led by the people who are part of the Company at all levels".

Male: "With opportunities to improve"

\subsubsection{Time Management Category}

Leaders must have the competence to manage their time, prioritizing objectives and activities in order to achieve goals.

Female: "Focus on work at work and on personal life after work" 
Male: "While in work I dedicate full time to complete the daily objectives. While outside, I focus in finding things that I like in order to relieve any kind of stress effect that work could have on me".

\subsubsection{Conflict Management Category}

Conflict is one of the most common issues in organizations and the leader must find ways to diagnose and solve quickly and efficiently the conflict without harming personal relations.

Female: “As a human. I listen and discuss the situation calmly, being objective and supportive to each side, showing willingness to move things forward

Male: "I contact, negotiate and request the information I need to explain the reason for my request".

\section{Findings and Conclusion}

The aim of the study was to compare the leadership competences of female and male Mexican expatriates using a qualitative approach to identify key differences. According to the narrative analysis it can be inferred that male and female Mexican expatriates have different leadership competences.

Regarding creative initiative competence the female leader has a more flexible position related to the group; while the male leader has a stronger attitude towards initiative. Something similar happens on the decision making competence in which the female refers to values and the male refers to a more competitive vision based on experience and advising.

On the Team Work competence, male leadership was pro-active; while the female attitude is oriented to training and communication. Additionally, Communication is a variable with a very formal position for the female participant; while for the male participant it is a very informal position. In terms of group, Empowerment competence was found to be similar in concept for both female and male participants, but the male added leadership as an important factor.

Regarding Customer Focus competence, it is a very formal situation for the female vision and it is based on information provided by the customer; while for the male vision it is about listening. On the other hand, Resilience competence is similar in both cases, considering leadership fundamental. Something similar occurs with Time Management competence where in both cases, they want to find a balance between work and personal life.

Concerning the Integrity competence there are opposing positions, for the female, the competence is based on values; while for the male, it is a competence based on opportunities. Finally, the Conflict Management competence is about listening according to the female participant; while for the male participant it is about negotiation.

Findings in narrative analysis let us infer that there are important differences between female and male leadership in Mexican expatriates. Three main different characteristics are highlighted for the male's leadership competences: receptive, leadership and informal. On the other hand, three contrasting characteristics are listed for the female: values, information and 
formality.

There is only one similar characteristic for both participants, female and male, and that is work and personal life, in the time management category. Both participants consider that it is important to have personal time especially in an expatriate position.

It is essential that companies develop programs to help expatriates to adapt easily in their new life. Also, it is important to understand the differences between female and male leadership between expatriates since they have different perspectives and motivations. In the case of the Mexican expatriates located in the USA, companies should not ignore the cultural background and its impact as it definitely has an influence on leaders' performances.

For future research, it is necessary to conduct a quantitative study on these findings, and also it would be relevant to research on the follower' viewpoint, but including the impact of Mexican culture on the performance of expatriates leaders. Moreover, the study could be extended to reveal differences in leadership between Mexican and Americans. These results may help organizations to successfully deal with the expatriates' immersion in the company's environment, with a view to developing adequate training programs for expatriates and families when necessary.

\section{References}

Ardichvili, A., Jondle, D., \& Kowske, B. (2010). Dimensions of ethical business cultures: comparing data from 13 countries of Europe, Asia, and the Americas. Human Resource Development International, 13(3), 299-315. https://doi.org/10.1080/13678868.2010.483818

Bealer, D., \& Bhanugopan, R. (2014). Transactional and transformational leadership behavior of expatriate and national managers in the UAE: a cross-cultural comparative analysis. International Journal of Human Resource Management, 25(2), 293-316. https://doi.org/10.1080/09585192.2013.826914

Berger, R., Choi, C., \& Kim, J. (2011). Responsible Leadership for Multinational Enterprises in Bottom of Pyramid Countries: The Knowledge of Local Managers. Journal of Business Ethics, 101(4), 553-561. https://doi.org/10.1007/s10551-011-0736-X

Black, J. S., \& Morrison, A. J. (2012). The Japanese global leadership challenge: what it means for the rest of the world. Asia Pacific Business Review, 18(4), 551-566. https://doi.org/10.1080/13602381.2012.690300

Cardona, P., \& García Lombardía, P. (2009). Como desarrollar las competencias de liderazgo. Navarra, España: EUNSA; IESE.

Cardona, P., \& Wilkinson, H. (2009). Creciendo como líder. Pamplona: EUNSA, IESE.

Chamoun-Nicolas Habid. (2005). La cultura de la negociación en México en http://www.gestiopolis.com/cultura-negociacion-mexico/. Fecha de consulta: 15 de abril de 2015.

Chaudhuri, S., \& Alagaraja, M. (2014). An expatriate’s perspective on leadership and leading 
(a global organization) in India: interview with Matt Barney. Human Resource Development International, 17(3), 358-365. https://doi.org/10.1080/13678868.2014.896125

Creswell, J. (2012). Educational Research. Planning conducting and evaluating quantitative and qualitative research. Pearson: Boston.

Dabic, M., González-Loureiro, M., \& Harvey, M. (2015). Evolving research on expatriates: what is "known" after four decades (1970-2012). International Journal of Human Resource Management, 26(3), 316-337. https://doi.org/10.1080/09585192.2013.845238

Dickson, M. W., Den Hartog, D. N., \& Mitchelson, J. K. (2003). Research on leadership in a cross-cultural context: making progress and raising new questions. The Leadership Quarterly, 14(6), 729-768. https://doi.org/10.1016/j.leaqua.2003.09.002

Eisenberg, J., Pieczonka, A., Eisenring, M., \& Mironski, J. (2015). Poland, a workforce in transition: Exploring leadership styles and effectiveness of Polish vs. Western expatriate managers. Journal for East European Management Studies, 20(4), 435-451. https://doi.org/10.5771/0949-6181-2015-4-435

Hsing-Chau, T., Lin-Yuan, C., \& Kuo-Hsun, Y. (2010). Current Research Paradigms in Expatriate(S) Research: A Bibliometric Approach. International Journal of Organizational Innovation, 2(3), 22-39.

INEGI. (2014). La Industria Automotriz en México 2014. Instituto Nacional de Estadística y Geografía. [Online] Available:

http://www3.inegi.org.mx/sistemas/biblioteca/ficha.aspx?upc=702825062552

Kawai, N., \& Mohr, A. (2015). The Contingent Effects of Role Ambiguity and Role Novelty on Expatriates' Work-related Outcomes. British Journal of Management, 26(2), 163-181. https://doi.org/10.1111/1467-8551.12089

Kim, H., \& Tung, R. L. (2013). Opportunities and challenges for expatriates in emerging markets: an exploratory study of Korean expatriates in India. International Journal of Human Resource Management, 24(5), 1029-1050. https://doi.org/10.1080/09585192.2012.753551

Krishnaveni, R., \& Arthi, R. (2015). An Overview of Multidimensional Factors Influencing Effective Performance of Expatriates. Management: Journal of Contemporary Management Issues, 20(2), 135-147.

Martin, G. S., Resick, C. J., Keating, M. A., \& Dickson, M. W. (2009). Ethical leadership across cultures: a comparative analysis of German and U.S. perspectives. Business Ethics: A European Review, 18(2). https://doi.org/10.1111/j.1467-8608.2009.01553.x

Nguyen, L., Boehmer, T., \& Mujtaba, B. (2012). Leadership and Stress Orientations of Germans: An Examination Based on Gender, Age, and Government Work Experience. Public Organization Review, 12(4), 401-420. https://doi.org/10.1007/s11115-012-0180-0

O’Sullivan, A., \& O’Sullivan, S. L. (2008). The performance challenges of expatriate supplier teams: a multi-firm case study. International Journal of Human Resource 
Management, 19(6), 999-1017. https://doi.org/10.1080/09585190802051287

Patrick, R. P., Jun, L., Juzek, C., \& Reiner, N. C. (2013). Fostering Job Satisfaction and Motivation through Power Distance: A study of German Expatriates' Leadership in China. Global Business \& Management Research, 5(4), 161-170.

Popovski, V., Popovska, M. B., \& Jovcheska, S. (2014). Factors Ranked By Expatriate Managers for Successful Implementation of International Tasks. Economic Development / Ekonomiski Razvoj, 16(3), 1-12.

ProMéxico. (2015). Inversión y Comercio. Te damos razones para invertir. [Online] Available: https://www.promexico.gob.mx/

Rodriguez, J. K., \& Scurry, T. (2014). Career capital development of self-initiated expatriates in Qatar: cosmopolitan globetrotters, experts and outsiders. International Journal of Human Resource Management, 25(7), 1046-1067. https://doi.org/10.1080/09585192.2013.815254

Stock, R. M., \& Özbek-Potthoff, G. (2014). Implicit leadership in an intercultural context: theory extension and empirical investigation. International Journal of Human Resource Management, 25(12), 1651-1668. https://doi.org/10.1080/09585192.2013.852605

Suutari, V. (1996). Variation in the average leadership behavior of managers across countries: Finnish expatriates' experiences from Germany, Sweden, France and Great Britain. International Journal of Human Resource Management, 7(3), 677-707. https://doi.org/10.1080/09585199600000150

Suutari, V. (1998). Leadership behavior in Eastern Europe: Finnish expatriates' experiences in Russia and Estonia. International Journal of Human Resource Management, 9(2), 235-258. https://doi.org/10.1080/095851998341071

Wolfendale, M. (2002). Doing Business in the Asia Pacific. Strategic Finance, 84(6), 26-330.

Wong, J., Wong, P. K., \& Li, H. (2007). An investigation of leadership styles and relationship cultures of Chinese and expatriate managers in multinational construction companies in Hong Kong. Construction Management \& Economics, 25(1), 95-106. https://doi.org/10.1080/01446190600632573

\section{Copyright Disclaimer}

Copyright for this article is retained by the author(s), with first publication rights granted to the journal.

This is an open-access article distributed under the terms and conditions of the Creative Commons Attribution license (http://creativecommons.org/licenses/by/3.0/). 